\title{
CICLOS DE MOBILIZAÇÃO POLÍTICA E MUDANÇA INSTITUCIONAL NO BRASIL ${ }^{1}$
}

\author{
Alberto Tosi Rodrigues \\ Universidade Federal do Espírito Santo
}

\begin{abstract}
RESUMO
O foco deste artigo é a interação entre mobilização e desmobilização política da sociedade, de um lado, e o processo de mudança na institucionalidade política, de outro. A hipótese básica é a de que ciclos de mobilização e ciclos de reforma institucional interagem, alimentando-se uns aos outros. Propõe a distinção de dois ciclos de mobilização: um ciclo de entrada e um ciclo de saída do regime militar instaurado em 1964. A eles corresponderam ciclos de reforma institucional com direções distintas.
\end{abstract}

PALAVRAS-CHAVE: mobilização política; instituições políticas; transição de regime; democracia.

\section{INTRODUÇÃO}

Este artigo pretende discutir a difícil relação entre a participação da cidadania mobilizada e a institucionalidade política produzida pela Constituição de 1988 a partir de um viés particular: a interação entre ciclos de mobilização política da sociedade (às vezes chamados na literatura de ciclos de protesto) e ciclos de mudança da ordem político-institucional.

Persigo esse objetivo em dois tempos: em primeiro lugar, uma discussão dos ciclos de mobilização e reforma institucional que marcaram a entrada no regime autoritário de 1964 e a saída dele; em seguida, uma discussão da tensão estabelecida na década de 1990 entre a nova ordem institucional e a crise de participação política, que presentemente bloqueia a completude do ciclo.

\footnotetext{
1 Versões anteriores deste trabalho foramapresentadas no II Encontro da Associação Brasileira de Ciência Política (ABCP), na PUC-SP, em novembro de 2000, e na mesaredondaConsolidaçãoda democracia: enfoquesteónicoseprocessos político-institucionais, realizada durante o Seminário Intemacional de Ciência Política: Política desdeel Sur, entre 3 e 5 de outubro de 2001 na Universidade Federal do Rio Grande do Sul (UFRGS). O evento foi organizado como patrocínio do Departamento de Ciência Política da UFRGS, do seu Programa de Pós-Graduação emCiência Políticae da Associação das Universidades do Grupo de Montevidéu. Sou grato a alguns de meus colegas de mesa nos dois encontros, em especial Marco Aurélio Nogueira, Bruno Pinheiro Wanderley Reis, Ricardo Silva, Carlos S. Arturi e Stéphane Monclaire, pelas sugestões e comentários.
}

Sidney Tarrow (1988; 1989), buscando o estabelecimento de uma interface conceitual entre mudanças institucionais e ativação política dos setores sociais organizados, formulou a noção de ciclo de protesto e reforma, que inspira o enfoque aqui adotado. Não voltarei a discutir o desenho conceitual dessa formulação ${ }^{2}$; basta frisar que os ciclos de mobilização politica de que tratarei estão demarcados pelas diferenças nos móveis da ação dos estratos sociais mobilizados e pelas diferenças nas estruturas de oportunidades e limitações conferidas pelos regimes políticos sob os quais se manifestaram.

\section{CICLOS DE MOBILIZAÇÃO E MUDANÇA INSTITUCIONAL NO BRASIL}

Proponho a consideração de dois grandes ciclos bastante nítidos de mobilização e mudança institucional em nossa história republicana, os quais, à falta de melhor denominação, apelidarei simplesmente de ciclo de entrada e ciclo de saída. Entrada e saída, no caso, são a entrada no regime autoritário de 1964 e a saída dele. O primeiro, assim, abrange o processo de incorporação das massas urbanas à participação política, desde os anos 30, passando pela ativação populista, até o golpe de 1964. O segundo refere-se ao "renas-

\footnotetext{
2 Para uma síntese do quadro conceitual aqui utilizado, ver aapresentação que fiz dos modelos deMchel DobryeSidney Tarrow e sua aplicação para o estudo da transição desse regime autoritário, emRodrigues (1999).
} 
cimento" da sociedade civil possibilitado pela eclosão dos "novos movimentos sociais" no bojo da transição de regime desde a década de 70 , que chega até a conjuntura da década de 1990 e não permite demarcar ainda, cremos, seu término.

Pode-se afirmar que em ambos os momentos configuraram-se ciclos de mobilização e de reforma do sistema político porque, nos dois casos, os processos de mobilização associaramse ao delineamento de situações críticas que incidiram diretamente sobre as mudanças estruturais que se operaram no perfil do regime.

Sobre o ciclo de entrada - considerando a vasta literatura disponível sobre mobilização social e regime político no período em torno do golpe de 1964 - basta frisar que nele o caráter do processo de mobilização é heterônomo, do ponto de vista dos móveis da ação política dos atores mobilizados, e que a resultante institucional ao final do ciclo foi a reciclagem das tecnologias estatais de contenção, e não uma reforma que institucionalizasse uma competição política ampliada. Não se afirma aqui que a mobilização foi a causa do golpe autoritário, mas antes que a relação entre o ciclo de mobilizações e o ciclo de reformas do sistema político desfavoreceu a continuidade da mobilização, na medida em que a solução institucional adotada foi altamente repressiva. Desfecho que certamente guarda relação com o desenvolvimento desigual e truncado das duas dimensões da poliarquia, a incorporação de novos atores (participação) e a institucionalização do conflito (liberalização).

A mobilização do ciclo de entrada pode ser dita heterônoma porque durante a incorporação desses novos atores urbanos, por via da prática populista e do corporativismo de Estado, como deixa claro a análise de Weffort, as massas "aparecem envolvidas em uma relação de manipulação: elas só servem à legitimação do Estado na medida em que, paradoxalmente, são também 'massas de manobra' para os grupos que controlam o poder; seus interesses sociais reais de classe só podem encontrar algum grau de expressão na medida em que politicamente ajustados e subordinados aos interesses dominantes. Enfim, sua autonomia de comportamento como classe não pode ir além dos limites impostos por essa relação de manipulação que - aí está a raiz do paradoxo - possibilita sua emergência no plano político" (WEFFORT, 1980, p. 123; grifo no original).

Essa situação contraditória em que se encon- tram os setores populares - isto é, ter na relação de manipulação o único canal para a expressão de seus interesses - ajuda a explicar, segundo Weffort, desde a identificação das massas com uma ideologia "supraclassista", como o nacional-desenvolvimentismo, até sua adesão "emotiva" a lideranças personalistas, ou ainda a ausência de uma representação política própria.

O modelo populista, porém, baseia-se num compromisso entre classes sociais e Estado, que se equilibra sobre um conjunto de pressões que provém tanto "de cima" como "de baixo". As camadas populares servem à legitimação do regime na medida em que pressionam por sua incorporação econômica e social, utilizando a política populista como canal, mas ao mesmo tempo trazem à cena pública todo o conjunto das insatisfações geradas pela "privação relativa", própria à modernização. $\mathrm{O}$ auge do nacional-desenvolvimentismo, na virada dos 50 para os 60 , funciona como o principal motor dessa mudança. Mobilizadas pelo populismo, ainda que parcialmente controladas pela estrutura corporativa, as camadas populares transformam-se, à medida que sua ativação intensifica-se, em uma ameaça potencial permanente ao status quo.

Assim, toda política populista paga um preço pela adesão popular, qualquer que seja a amplitude de sua capacidade de manipulação. Ela deve assumir, no plano político, responsabilidades com a democratização do Estado, e, no plano econômico, um compromisso com a expansão das possibilidades de consumo, o que impõe no mínimo uma política de crescimento do emprego. Em outras palavras, ela deve ser capaz pelo menos de garantir a preservação e a intensificação do ritmo do desenvolvimento econômico e social que anteriormente propiciaram o surgimento das classes populares e que agora mantêm a vigência das alianças populistas (WEFFORT, 1980, p. 163).

Essa observação de Weffort, note-se, lembra que há uma correlação potencialmente direta entre o perfil político e econômico do Estado - enquanto poder público e enquanto pacto de dominação social -, a estrutura de oportunidades e limitações à ação política oferecida pelo regime democrático e, finalmente, o processo de mobilização política da sociedade.

Sabemos que o Estado brasileiro do período não foi capaz de manter o mesmo ritmo de crescimento e de incorporação sócio-econômica. 
Quando o processamento irresponsável ${ }^{3}$ das demandas "de baixo" inviabilizou-se, inclusive em função das próprias dificuldades interpostas pela mobilização social à continuidade do processo ampliado de acumulação, abriu-se uma situação instável que conjugou as mobilizações à incidência de várias crises - de governo, de regime e, como possibilidade-limite, de dominação social - e culminou na solução institucional de 1964. Expirada a capacidade populista-corporativa de contenção das mobilizações em níveis aceitáveis, os militares forjaram, em especial a partir de 1968, novas tecnologias de contenção, notadamente por intermédio de um aprofundamento da corporativização, além da repressão política pura e simples. Guillermo O'Donnell descreve com precisão o caráter dessa conjuntura crítica (O'DONNELL, 1990, p. 41-60), na qual a imprevisibilidade econômica amalgamouse à "ativação do setor popular" e aprofundou a instabilidade "pretoriana", em princípio instaurada no nível do governo e em seguida em direção a uma crise de proporções maiores. A partir das expectativas negativas gestadas aí é que se definiu o grau de fechamento político do novo regime autoritário.

Já os resultados institucionais do ciclo de saída, de outra parte, materializaram-se nas conquistas democráticas paulatinamente obtidas durante a transição, a partir de 1974 (cf. VELASCO E CRUZ \& MARTINS, 1983), e estenderam-se, em termos gerais, ao processo constituinte de 198788. Mas não se esgotaram nele - e esse é o ponto central para nossa periodização.

Do ponto de vista dos móveis da ação e da relação dos novos atores - que se incorporaram a si próprios ao jogo - com as elites políticas já em competição, pode-se falar, em contraste com o ciclo de entrada, num processo de mobilização predominantemente autônomo. Esse novo caráter da mobilização observada nesse segundo ciclo está associado à constituição, em seu nascimento e desenvolvimento inicial, de um novo tipo de cultura política e de ética pública, próprias ao campo social então articulado.

QUADRO I

\begin{tabular}{|c|c|c|}
\hline & Ciclo de entrada & Ciclo de saída \\
\hline Caráter da mobilização & Heterônoma & Autônoma \\
\hline Resultante institucional & Contenção & Liberalização \\
\hline
\end{tabular}

Note-se que, do ponto de vista do tratamento das demandas sócio-econômicas dos "de baixo", o regime autoritário pagou também seu preço pela exclusão dos setores populares, exclusão que se viabilizara com o recrudescimento da contenção desses setores por via do corporativismo sindical e da repressão política. Vale a pena recordar, a propósito, que as greves do $\mathrm{ABC}$ paulista que eclodiram a partir de 1977 deram-se no bojo de uma campanha por reposição salarial que não encontrou na estrutura corporativo-repressiva canais adequados de processamento. As conseqüências políticas dessa ausência de canais são conhecidas. Mas, por outra, o regime autoritário só pagou esse preço político a partir do momento em que as pressões de ordem econômica desenca-

\footnotetext{
3 Imesponsável porque, como notou Wanderley Guilherme dos Santos, a delegação desse processamento à burocracia fez que seu custo fosse socializado e seus proventos privatizados pelos políticos populistas. A formulação das políticas sociais no pós-30, portanto, não obedeceua qualquer mecanismode garantiadeaccountability mínima que permeasse o processo de representação política (cf. SANTOS, 1993).
}

deadas pela crise do "milagre" deram sua contribuição à ativação política dos setores operários de ponta - o que nos remete, por sua vez, à crise do Estado e do modelo de desenvolvimento, e suas relações com esse ciclo de mobilizações, como veremos mais abaixo.

Mas antes é importante frisar que os movimentos sociais urbanos tiveram nesse momento um papel fundamental. No desenvolvimento do que chamamos aqui de ciclo de saída, os conflitos políticos que envolveram de algum modo a estruturação dos agentes sócio-políticos e sua mobilização estiveram sujeitos à presença, como notou Doimo (1995), de atores coletivos dotados de longevidade e densidade política muito diversas: "desde aqueles que se esvaziam junto com o próprio esgotamento do circuito reivindicativo, até aqueles que ganham fôlego e passam a marcar presença no espaço público" (idem, p. 66). Conforme a perspectiva de Tarrow, quando a persistência de práticas de mobilização ganha corpo e visibilidade na arena política nacional, isto é, torna-se parte da "grande política”, "já não estamos mais diante de meras 
ações-diretas e sim de campos ético-políticos ou de redes sociais que criam energias sócio-políticas e recursos de poder, capazes de influir nos padrões culturais e nas formas de convivência política. [...] [No Brasil,] extensas redes sociais desenharam, entre os anos 1975-1990, um expressivo campo ético-político à base de movimentos reivindicativos de ação-direta, auto-reconhecido como movimento popular, mediante apoio de significativos setores da Igreja Católica, do ecumenismo, de segmentos da academia científica e grupamentos de esquerda, estes quase sempre inseridos nas chamadas ONGs, organizações não-governamentais" (idem, p. 6667).

Talvez uma das mais significativas peculiaridades deste novo campo ético-político esteja no fato de que as elaborações discursivas e as práticas efetivas dos movimentos populares - assim como as do novo sindicalismo - negavam o padrão institucional e cultural clientelístico-corporativo prevalente no ciclo de entrada, bem como os aspectos mais autoritários desse padrão, reapropriados, reelaborados e ampliados pelo regime militar. No caso do novo sindicalismo, os trabalhadores foram capazes de elaborar estruturas organizacionais "a partir da base" e por fora da institucionalidade permitida pelo corporativismo estatal. Não deixaram tampouco de fazer a crítica do uso corporativista das políticas sociais: "A CLT é o AI-5 dos trabalhadores", afirmou o sindicalista Lula (apud MUNAKATA, 1984, p. 106). A essa estrutura corporativista o novo sindicalismo agregou (embora de fato sem romper com ela por inteiro) formas autônomas de representação corporativa dos trabalhadores, que se consubstanciaram na formação das centrais sindicais, notadamente a Central Única dos Trabalhadores (CUT), no início dos anos 80. Nessa mesma época a persistência da concentração da propriedade rural e o processo de proletarização no campo ocorrido nos anos 70 deu vez ao surgimento do Movimento dos Trabalhadores Rurais Sem-Terra (MST); contra as permanências institucionais residuais do coronelismo e do populismo, esses movimentos cultivaram um forte sentimento autonomista.

Mas, para além da negação do clientelismo ou do corporativismo estatal, creio ser possível afirmar que tais movimentos populares e sindicais contribuíram efetivamente para a conformação de novas atitudes para com o "fazer política", estruturadas a partir do investimento na socialização do conflito político e no compartilhamento de uma ética pública solidária, tendências que tiveram desde o início, como horizonte institucional, a democracia ${ }^{4}$. Nesse sentido, mesmo forjando, em seu nascimento, um forte caldo de cultura antiinstitucional, os movimentos populares ajudaram a montar - justamente na medida em que constituíram um campo ético-político - um novo paradigma discursivo e um novo estoque de práticas políticas que incidiram sobre o comportamento dos atores presentes na arena política nacional, notadamente a oposição democrática ao regime militar, liberais ou esquerda.

A intervenção pública deste campo plasmado no bojo do ciclo de saída do autoritarismo ajudou a moldar o comportamento de atores que, em boa medida, foram chamados a participar (e de fato participaram) dos pactos fundantes da institucionalidade reclamada pela democracia pós-1985. E fizeram-no, para valer-me uma vez mais da interpretação de Doimo, na medida em que, "para além das reivindicações locais e pontuais, influíram nos padrões de convivência política" (1995, p. 68). Mesmo reconhecendo, portanto, o discurso de recusa às instituições, deve-se encarar a formação de um tal campo ético-político como um fenômeno conjuntural que, se tem sua face "expressivodisruptiva, pela qual se manifestam valores morais ou apelos ético-políticos tendentes a deslegitimar a autoridade pública", por outro lado também apresenta sua face "integrativo-corporativa, pela qual se buscam conquistar maiores níveis de integração social pelo acesso a bens e serviços" (idem, p. 69). Foi essa última face a que se deparou diretamente com a crise do Estado que se agrava

\footnotetext{
${ }^{4}$ Reconheço que háumagrande dificuldade conceitual para se falar em movimentos populares como vetores de uma ética pública tendente a favorecer a construção de instituições poliárquicas. Afinal, um associacionismo de tipo tocquevilleano implica necessariamente algum amor pelas instituições da democracia representativa, e, como sabemos, tais movimentos pautaram-se, antes e de modo geral, pela recusa, pelo estranhamento e mesmo pelo repúdio deliberado aos canais institucionais "formais". Para Ana Maria Doimo, aliás, "a própria natureza dos conflitos de ação-direta, ao prescindir do sistema de representação política, abre terreno fértil para o florescimento de valores morais em substituição aos conceitos políticos" (DOIMO, 1995, p. 68). Mas há que se distinguir entre os discursos produzidos pelas lideranças "movimentalistas" e o saldo da intervenção prática dos movimentos sobre a institucionalidade política e, inclusive, sobre as concepções e estratégias de outros atores políticos mais diretamente preocupados com a montageminstitucional democrática
} 
a partir da década de 1980. Assim, vê-se que a ênfase por vezes colocada, por parte dos militantes, na "deslegitimação" da autoridade pública deve ser compreendida como a recusa ao autoritarismo instaurado no nível do regime e como crítica à política econômica dos últimos governos militares. O que se mostra fundamental para meu argumento é, antes, o outro lado da moeda, a saber, o fato de que "em conjunturas mais democráticas, em que o sistema político se torna mais sensível e permeável às demandas", os movimentos populares - $\mathrm{e}$, poder-se-ia dizer, a mobilização da cidadania ativa de um modo geral - podem até mesmo "apontar a possibilidade de se estabelecerem novos arranjos político-institucionais de perfil democrático, visando à formatação dos conflitos e à canalização das demandas" (ibidem; sem grifos no original).

Talvez valorizemos mais adequadamente o fenômeno se lembrarmos que as bases sobre as quais é possível o pleno desenvolvimento das instituições políticas poliárquicas são justamente o pluralismo societal e o universalismo de procedimentos; no que tange às relações entre público e privado, entre Estado e sociedade. Há uma incompatibilidade de nascença entre a poliarquia e a tutela do Estado sobre a sociedade - em especial se a estruturação desse Estado deu-se em moldes patrimonialistas - tutela da qual decerto deriva boa parte das enormes dificuldades de institucionalização da democracia brasileira no presente. Talvez possamos compreender melhor os desdobramentos do conflito político na Nova República e de depois dela, se recordarmos que os "novos arranjos institucionais" que seriam compatíveis com uma expressão plena deste novo campo ético-político no sistema político formal foram, afinal, preteridos em favor de pactos políticos firmados entre elites políticas que se investiram da condição de fiadoras da transição. Para retomar os termos que utilizei em outro trabalho (RODRIGUES, 1993b), o saldo da derrota da campanha das Diretas foi o de que a "lógica da negociação" prevaleceu sobre a "lógica da ruptura". Padrão que obedeceu, nesse particular, à indelével vocação elitista da tradição política brasileira.

Está para ser feito um balanço adequado do preço pago - pela cidadania e pela institucionalidade democrática - por essa opção pela entrada na democracia "por meios não-democráticos", para usar a expressão de O'Donnell e Schmitter.

Note-se que a questão fundamental aqui não é a valorização de ações supostamente espontâneas do povo contra algum conservadorismo maquiavélico das elites. Sabemos que o momento inicial do ciclo de mobilização de saída do autoritarismo - cuja imagem mais eloqüente talvez tenha sido a do "povo como sujeito de sua própria história" foi o leito para o qual confluíram, vale a pena repetir, em função do bloqueio dos canais institucionais rotineiros, diversos atores políticos relevantes, como sindicalistas, intelectuais, militantes de organizações de esquerda e religiosos, que canalizaram suas energias represadas para o associativismo e o "movimentalismo" ascendentes. A elaboração discursiva e política que ajudaram a construir pautou-se, em vista dessa situação, pela lógica da ampliação do conflito político.

"Ao interpretar as coordenadas estruturais do seu tempo, ao processar as novas influências intelectuais e correntes européias de pensamento, ao estabelecer um diálogo crítico com a tradicional cultura política autoritária brasileira, bem como ao resgatar e revalorizar outros traços da tradição cultural - comunidade, relações interpessoais -, esses atores recuperaram de tal sorte a capacidade ativa do 'povo' que conseguiram não só colocálo no centro da elaboração teórica como promovêlo a personagem central da vida política" (DOIMO, 1995, p. 75; sem grifos no original).

Creio que não faz sentido, portanto, concebêlos simplesmente como atores interessados em manter-se como marginais à institucionalidade. Pelo contrário, sua vocação expressou-se, em diversas situações empíricas, em diferentes níveis de abrangência, no sentido de contribuir para a estruturação de novos canais institucionais, que incorporassem a cidadania ativa ao conflito. A concepção de democracia que subjaz a este tipo de prática, por sua vez, contrasta fortemente com a da maior parte das elites egressas da competição restrita do autoritarismo, responsáveis pelos pactos da transição. Para essas últimas, a melhor palavra de ordem democrática teria sido uma corruptela da célebre frase de Antônio Carlos (o de 1930): "façamos a democracia antes que o povo a faça".

Assim se fez. E aí reside uma sugestão interessante, creio, para perceber-se o caráter da incompletude da institucionalização do novo regime democrático. E é por isso, entre outras coisas, que o ciclo de mobilizações vinculado à saída do regime autoritário não se esgota com o advento do governo civil da Nova República. 
III. CRISE DO ESTADO, REFORMAS ORIENTADAS PARA O MERCADO E DESINSTITUCIONALIZAÇÃO DEMOCRÁTICA: O CICLO INCONCLUSO

Por que o ciclo de saída do regime militar deve ser considerado um ciclo inconcluso?

A fase inicial do ciclo de mobilizações que marca a saída do autoritarismo apresenta uma trajetória ascendente, do ponto de vista da participação social "de baixo para cima" - incremento do associativismo em geral, novos movimentos sociais, novo sindicalismo - e uma liberalização da estrutura de oportunidades oferecida pelo sistema político institucional "de cima para baixo" - a distensão e a abertura. Essa conjugação de dinâmicas viabilizou a emergência de uma situação crítica, que pode ser chamada de conjuntura política fluida (cf. DOBRY, 1983; 1986), cujas características empíricas sumariei em outro trabalho (RODRIGUES, 1999). É o momento que envolve a campanha das "Diretas-Já" (cf. RODRIGUES, 1993b; 1995). Este episódio de ampla mobilização de massa tem um perfil que poderia, à primeira vista, ser interpretado como o clímax do ciclo de saída do regime autoritário, ao qual se seguiria uma desmobilização que encerraria o ciclo.

Isso seria assim se concebêssemos a Nova República como o ponto final da "transição" e o início da mal-chamada "consolidação" democrática. E se concebêssemos o movimento geral do ciclo, como no modelo de O'Donnell e Schmitter, desdobrado em três fases. Uma primeira fase de ascensão em que se dá o processo de mobilização funcionalmente adequado à tarefa de "forçar as portas fechadas" do regime autoritário rumo à liberalização; uma segunda fase (o clímax), na qual o entrecruzamento de diversos processos parciais de mobilização culminariam na emergência de grandes movimentos de massa na cena pública (como a campanha das Diretas), pondo em xeque o regime; e uma terceira fase em que o regime se desagrega e precipita o surgimento de um poder civil por via de um pacto entre moderados do regime e da oposição. Isso culminaria, por sua vez, com o estabelecimento de um novo quadro normativo democrático, como o da Constituição de 1988, simétrico ao descenso das mobilizações. Os ciclos de mobilização e reforma se entrecruzariam, alimentar-se-iam um ao outro e, afinal, revelariam sua complementaridade. Seguindo por essa trilha, concluiríamos que após a Nova República as mobilizações da "transição" seriam devidamente substituídas pela "rotinização" do conflito, pela "normalização" do regime democrático e, portanto, pela "desmobilização" social, uma vez que a mobilização tornar-se-ia então funcionalmente desnecessária. A desmobilização seria, a julgar por esse padrão, a contrapartida esperada da institucionalização dos canais "normais" da competição política, típica da "consolidação" democrática.

Uma rápida olhada nos eventos que marcaram a cena política nas décadas de 80 e 90, porém, basta para revelar que não é disso que se trata. A batalha é bem mais longa do que esse modelo faria crer. Além disso, o que é mais importante - a compreensão do alongamento do perfil desse ciclo de mobilização e reforma-depende da consideração de outros elementos que não exclusivamente a montagem da institucionalidade formal.

Do ponto de vista aqui adotado, as potencialidades de mudança institucional trazidas à luz do dia pelas mobilizações que tiveram na campanha das Diretas seu ápice - e penso que essa virtualidade coincide no mínimo com um padrão poliárquico - não encontraram resposta compatível no sistema político que se institucionalizou a partir da Nova República e que se desdobrou nas eleições e nos outros eventos políticos subsequientes (o "híbrido institucional" de que fala Wanderley Guilherme). É justamente o fato de as mobilizações não terem encontrado resposta que as fez ressurgir nos anos de 1989, durante a campanha eleitoral, e 1992, durante a campanha pelo impeachment.

Penso, procurando formular o problema de modo sintético, que essas situações de mobilização - de 1989 e 1992 - e as de desmobilização-planos Collor, de 1991, e Real/eleições de 1994 -, eventoschave da conjuntura pós-Constituição de 1988, prendem-se ainda ao problema da democratização tal como colocado pela mobilização das "Diretas$J a ́$ "5. As respostas institucionais dadas na Nova República e no governo Collor deixaram o ciclo em aberto. Dito de outro modo: nos anos 90, tanto as mobilizações, cujo sentido advogo, foi o de pressionar o sistema político em direção à ins-

\footnotetext{
5 Não me refiro, evidentemente, à reivindicação específica de realização de eleições diretas paraPresidente da República Refiro-me ao fato de a mobilização das "Diretas-Já" ter trazido ao espaço público o "espírito" da república democrática, da exigência social por uma ordemdemocrática participativa.
} 
titucionalização do universalismo de procedimentos e de mecanismos participativos; quanto as respostas às mobilizações engendradas pelos atores alocados no Estado, cujo sentido defendo, foi o de reafirmar, conforme a conveniência, as lógicas do clientelismo ou do insulamento burocrático (cf. NUNES, 1997), inscrevem-se num quadro conflitivo cujo cerne é a disputa pelo tipo de instituições e práticas políticas que devem ser aceitas como reguladoras da competição democrática, e não a disputa "rotinizada", regrada por instituições de perfil poliárquico consensualmente aceitas, que supostamente canalizariam as pressões "de baixo" para dutos "adequados".

Numa palavra, a agenda política posta pela campanha das Diretas, no topo da qual está a institucionalização de uma democracia participativa, continua em aberto.

E mais. Se considerarmos que a promessa básica sobre a qual erigiu-se a Nova República foi a da conjugação entre democracia política e eqüacionamento das desigualdades sócio-econômicas, o "resgate da dívida social", teremos que lembrar necessariamente o impacto da crise do Estado brasileiro em meio ao qual cambaleou a década de 80. A propósito, Brasílio Sallum (SALLUM JR., 1995 ; 1996) chamou atenção para o fato de que o fracasso dos planos de estabilização monetária deflagrados nos anos 80 está diretamente ligado ao fato de que são tentativas políticas de resolver um problema que tem por base a crise do Estado desenvolvimentista dentro dos quadros desse mesmo Estado desenvolvimentista. Essa situação aponta para a indissociabilidade, na tentativa de compreender essa conjuntura, entre os movimentos de montagem do novo aparato institucional democrático, as tentativas de superação dos problemas econômicos interpostos pela crise do Estado e o novo padrão de participação autônoma da sociedade organizada.

Há uma relação freqüientemente esquecida entre a eclosão da participação política autônoma durante o que aqui chamei de ciclo de saída do regime autoritário, por um lado, e a crise do Estado desenvolvimentista, por outro. Uma relação que se verifica exatamente na reação política da sociedade organizada à centralização decisória própria à implementação das políticas econômicas. Como assinalou Brasílio Sallum, "o novo padrão associativo e suas práticas - além de pôr em xeque diretamente a capacidade do Estado regular como antes a so- ciedade, tornando mais flexíveis os controles corporativos tradicionais - expressam em geral o descompasso entre a complexidade crescente da sociedade e os mecanismos de representação/cooptação política até então vigentes, apontando para o anacronismo do Estado desenvolvimentista vigente e do regime militar" (SALLUM JR., 1995, p. 154).

Se os novos movimentos sociais dos países capitalistas centrais podem ser lidos como reações à crise do Welfare State, os movimentos populares brasileiros são já reações à crise do modelo nacional-desenvolvimentista. Sabemos que o desenvolvimentismo, assim como o corporativismo, foi retomado como política de Estado durante o regime militar, embora com transformações importantes com relação ao período anterior. Tanto o "milagre econômico" quanto a reação a sua crise, nos anos 70 (reação cujo principal instrumento foi o II PND), deram-se nos quadros do pacto desenvolvimentista. Esse nacional-desenvolvimentismo - uma ideologia "supraclassista" pensada, nos anos 50, como articulada à prática populista e à estrutura corporativista estatal, no que concerne à contenção da mobilização dos trabalhadores foi objeto, nos 70 , do contraponto político dos movimentos populares, justamente naquilo que diz respeito a um de seus aspectos mais importantes e duradouros (que inclusive sobreviveu à própria crise do desenvolvimentismo), a saber, a ideologia tecnocrática, à qual se associa, por sua vez, uma lógica de comportamento político própria aos gestores da burocracia econômica brasileira, a lógica do insulamento burocrático. Como lembrou Doimo, com a estruturação do campo éticopolítico no início do ciclo de saída do autoritarismo, "de uma concepção passiva e quase objetal da participação [...], inaugura-se uma concepção centrada na capacidade ativa do povo, pela qual não havia mais lugar [...] para o culto do 'Estadonação', que prometia o desenvolvimento pela eficácia instrumental-administrativa do planejamento compreensivo" (DOIMO, 1995, p. 76; sem grifos no original).

Da prática dos movimentos e do novo sindicalismo emanou a primeira reação política da sociedade organizada à crise do Estado desenvolvimentista, que se orientou em sentido diametralmente oposto ao do consenso que se instauraria no seio das elites empresariais e da direita partidária, nos anos 80 .

Em suma, do dito acima se depreende que o 
conflito político que perpassou a sociedade e o sistema político na virada dos anos 80 aos 90 , ao mesmo tempo em que esteve marcado pela continuidade da competição acerca do caráter das instituições políticas do regime democrático, sofreu também os impactos da crise do Estado desenvolvimentista, em resposta à qual se podem vislumbrar alternativas tanto pelo lado da sociedade organizada quanto pelo lado das elites.

Tal crise, por sua vez, é incompreensível apartada das circunstâncias da ampla mudança histórica observada no capitalismo internacional. A agenda política dominante, desenvolvida como resposta à crise do capitalismo central nos anos 70, passou por um período de encubação entre as elites empresariais e da direita política brasileiras (o período da "produção do consenso" - cf. VELASCO E CRUZ, 1994) até ganhar força suficiente para intervir de modo decisivo sobre o conflito político posto na arena nacional, e que ganhou apelo público nas eleições de 1989 e nos anos de Collor, sob a forma do discurso em favor do Estado mínimo e das reformas orientadas para o mercado.

Quando a década de 90 principiou, estavam já configuradas, politicamente ativadas e inextrincavelmente articuladas a crise do Estado, a crise da institucionalidade política formal (recém instaurada com a Constituição de 1988) e a crise de participação social. Enquanto a crise do Estado solicitou à institucionalidade formal instrumentos políticos que ampliassem a margem de manobra dos gestores da economia e lhes facilitassem o acesso a meios governativos efetivos, a crise de participação social solicitou a essa mesma institucionalidade que incorporasse, através de canais formais, o novo padrão de conduta dos setores populares e a nova abrangência do conflito social. Não se pode falar numa crise do regime democrático, mas ao falar em crise da institucionalidade política formal pretendo destacar o fato de que ela era objeto de uma disputa a respeito de seu caráter: se compatível com a centralização administrativa e o insulamento burocrático exigidos pela gestão econômica das crises fiscal, monetária e de pagamento da dívida externa ou se aberta à ampliação dos canais de expressão e processamento das demandas substantivas da sociedade exigidos pelo novo padrão de mobilização da sociedade organizada.

Assim, se a agenda política não cumprida pela Nova República apontava para a urgência de respostas políticas legítimas, que ancorassem e enraizassem o processo democrático formal nas novas práticas participativas articuladas pela cidadania ativa, por outro lado a agenda econômica igualmente não cumprida exigia respostas politicas eficazes, que equacionassem de imediato ao menos o problema da estabilização monetária, senão da crise do Estado.

Dito isso, é possível entender porque o cerne do conflito político que se desenrolou na conjuntura da virada dos anos 80 para os 90 foi o conflito entre os atores situados no Executivo que, a partir da lógica do insulamento burocrático, buscaram dotar a burocracia econômica de instrumentos políticos eficazes, e os atores situados na sociedade organizada e na esquerda partidária que, a partir da lógica do universalismo de procedimentos, buscaram efetivar canais participativos de competição política. Os primeiros, contra os segundos, agem na conjuntura em aliança com os atores $d a$ direita partidária situados no Parlamento que, a partir da lógica do clientelismo tradicional, buscam no acesso privilegiado aos recursos públicos a manutenção de sua ascendência sobre os amplos setores inorgânicos da sociedade que lhes servem de base eleitoral.

De um lado, a lógica da eficácia econômica; de outro, a lógica da legitimidade político-jurídica. De um lado, o discurso da governabilidade, de outro, o reclamo por mobilização social. De um lado, o interesse numa competição política cujo eixo estivesse no tema da estabilização monetária; de outro, o interesse numa competição política cujo eixo estivesse no tema da "ética na política".

Após o atabalhoado período Collor, o consenso do Estado mínimo finalmente chegou, com Fernando Henrique, ao governo, e em condições de viabilidade política. A crise do Estado passou a ter desde então um eqüacionamento consistente com a ideologia e o programa das forças políticas que lhe deram suporte. A crise de participação, porém, continua desde então sem eqüacionamento algum e o rumo apontado pelos resultados eleitorais de 1994 (e também de 1998) é antes o da desmaterialização das próprias demandas sociais constitucionalizadas em 1988. Em vez da estruturação de uma nova ordem participativa, vislumbrou-se a perspectiva da desinstitucionalização democrática.

Talvez o saldo dos conflitos da conjuntura compreendida entre as duas primeiras eleições 
diretas para Presidente da República desde 1960 ajude a compreendermos porque a mobilização política da sociedade não se tornou funcionalmente desnecessária frente à normalidade da "consolidação democrática". E porque, afinal, apenas uma fina e tênue película formalmente poliárquica recobre hoje o núcleo duro da democracia brasileira.

Recebido para publicação em 8 de outubro de 2001. Artigo aprovado em 23 de novembro de 2001.

Alberto Tosi Rodrigues (tosi@politica.pro.br) é Doutor em Ciências Sociais pela Universidade Estadual de Campinas (Unicamp) e Professor de Ciência Política na Universidade Federal do Espírito Santo (UFES).

\section{REFERÊNCIAS BIBLIOGRÁFICAS}

ALMEIDA, M. H. T. 1989. Direitos sociais, organização de interesses e corporativismo no Brasil. Novos Estudos CEBRAP, São Paulo, n. 25 , p. $50-60$, out.

1996. Pragmatismo por necessidade : os rumos da reforma econômica no Brasil.Dados, Rio de Janeiro, v. 39, n. 2.

BACHRACH, P. \& BARATZ, M. S. 1969. Two Faces of Power. In : CONNOLY, W. (ed.). The Bias of Pluralism. New York: Atherton Press.

BAER, M. 1993. O rumo perdido : a crise fiscal e financeira do Estado brasileiro. Rio de Janeiro : Paz e Terra.

BEETHAN, D. 1994. Key Principles and Indices for a Democratic Audit. In : (ed.). Defining and Measuring Democracies. London : Sage.

BENEVIDES, M. V. M. 1991. A cidadania ati$v a$ : referendo, plebiscito e iniciativa popular. São Paulo : Ática.

BIRNBAUM, P. 1983. Mobilisations, structures sociales et types d'État. Revue Française de Sociologie, Paris, v. XXIV, n. 3.

BOSCHI, R. R. 1987. A arte da associação : política de base e democracia no Brasil. São Paulo/Rio de Janeiro : Vértice/IUPERJ.

CAMARGO, A. \& DINIZ, E. 1989. Dilemas da consolidação democrática no Brasil. In : (orgs.). Continuidade e mudança no Brasil da Nova República. São Paulo : Vértice.

CARDOSO, R. C. L. 1990. Participação política e democracia. Novos Estudos CEBRAP, São Paulo, n. 26, p. 15-24, mar.
CARVALHO, J. M. 1997. Interesses contra a cidadania. In : DAMATTA, R. (org.). Brasileiro : cidadão? $5^{\mathrm{a}}$ ed. São Paulo : Cultura.

CHAZEL, F. 1975. La mobilisation politique : problèmes et dimensions. Revue Française de Science Politique, Paris, v. XXV, n. 3.

DAHL, R. A. 1971. Polyarchy: Participation and Opposition. New Haven : Yale University Press.

1989. Democracy and Its Critics. New Haven : Yale University Press.

DINIZ, E. 1985. A transição política no Brasil : uma reavaliação da dinâmica da abertura. Dados, Rio de Janeiro, n. 26.

. 1997. Crise, reforma do Estado e governabilidade : Brasil, 1985-95. Rio de Janeiro : Fundação Getúlio Vargas.

DINIZ，E. \& BOSCHI，R. R. 1991. O corporativismo na construção do espaço público. In : BOSCHI, R. (org.). Corporativismo e desigualdade : a construção do espaço público no Brasil. Rio de Janeiro : IUPERJ/Rio Fundo.

DOBRY, M. 1983. Mobilisations multisectorielles et dynamique des crises politiques : un point de vue heuristique. Revue Française de Sociologie, Paris, n. XXIV.

. 1986. Sociologie des crises politiques. Paris : Presse de la Fondation Nationale des Sciences Politiques.

DOIMO, A. M. 1995. A vez e a voz do popular : movimentos sociais e participação política no Brasil pós-70. Rio de Janeiro : Relume-Dumarál ANPOCS. 
FARIA, J. E. 1993. Direito e economia na democratização brasileira. São Paulo : Malheiros.

1989. O Brasil pós-Constituinte. São Paulo: Graal.

FREY, F. W. 1985. The Problem of Actor Designation in Political Analysis. Comparative Politics, New York, v. 17, n. 2.

GAMSON, W. A. 1968. Power and Dinscontent. Homewood. : Dorsey Press.

1990. The Strategy of Social Protest. $2^{\mathrm{a}}$ ed. Belmont (CA) : Wadsworth.

HAGOPIAN, F. 1990. Democracy by Undemocratic Means? Elites, Political Pacts and Regime Transition in Brazil. Comparative Political Studies, v. 23, n. 2, July.

HINDESS, B. 1982. Power, Interests and Outcome of Struggles. Sociology, v. 16, n. 4.

KECK, M. 1988. O "novo sindicalismo" na transição brasileira. In : STEPAN, A. (org.). Democratizando o Brasil. Rio de Janeiro : Paz e Terra.

1991. PT, a lógica da diferença: o Partido dos Trabalhadores na construção da democracia brasileira. São Paulo : Ática.

LAPEYRONNIE, D. 1989. Changements et mobilisations politiques. Information sur les Sciences Sociales, v. 28, n. 2, juin.

LESSA, R. 1989. Fados de um republicídio. In : CAMARGO, A. \& DINIZ, E. (orgs.). Continuidade e mudança no Brasil da Nova República. São Paulo : Vértice.

LICHBACH, M. I. 1998. Contending Theories of Contentious Politics and the StructureAction Problem of Social Order. Annual Review of Political Science, Palo Alto (CA), v. 1.

LIPSKY, M. 1970. Protest in City Politics. Chicago : Rand/McNally.

LOUREIRO, M. R. 1997. Os economistas no governo : gestão econômica e democracia. Rio de Janeiro : Fundação Getúlio Vargas.

MANN, P. 1991. L'action collective : mobilisation et organisation des minorités actives. Paris : Armand Colin.

MUNAKATA, K. 1984. A legislação trabalhista no Brasil. $2^{\mathrm{a}}$ ed. São Paulo : Brasiliense.
NUNES, E. 1997. A gramática política do Brasil : clientelismo e insulamento burocrático. Rio de Janeiro/Brasília : Jorge Zahar/ENAP.

O'DONNELL, G. 1976. Sobre o 'corporativismo' e a questão do Estado. Cadernos DCP, Belo Horizonte, n. 3.

1990. Análise do autoritarismo burocrático. Rio de Janeiro : Paz e Terra.

. 1996. Illusions about Consolidation. Journal of Democracy, Baltimore, v. 7, n. 2, p. 34-51, Apr.

O'DONNELL, G. \& SCHMITTER, P. C. 1988. Transições do regime autoritário : primeiras conclusões. São Paulo : Vértice.

OBERSCHALL, A. 1973. Social Conflict and Social Movements. Englewood Cliffs (New Jersey) : Prentice Hall.

OFFE, C. 1985. New Social Movements : Challenging the Boundaries of Institutional Politics. Social Research, New York, v. 52.

OLSON, M. 1978. Logique de l'action collective. Paris : Presses Universitaires de France.

OVERBEEK, H. \& VAN DER PIJLS, K. 1993. Restructuring Capital and Restructuring Hegemony. Neo-Liberalism and the Unmaking of the Post-War Order. In : OVERBEEK, $\mathrm{H}$. (ed.). Restructuring Hegemony in the Global Political Economy. The Rise of Transnational Neo-Liberalism in the 1980's. London/New York : Routledge.

PRZEWORSKI, A. 1984. Ama a incerteza e serás democrático. Novos Estudos CEBRAP, São Paulo, n. 9, p. 36-46, jul.

RODRIGUES, A. T. 1993a. Estudantes na política, em tempos de mobilização e crise. São Paulo em perspectiva, São Paulo, v. 7, n. 1, p. 138-144, jan.-mar.

.1993b. Mobilização e conflito político : a campanha das “Diretas Já”. Campinas. Dissertação (Mestrado em Ciência Política). Instituto de Filosofia e Ciências Humanas, Universidade Estadual de Campinas.

.1994. Modelos analíticos em teoria das mobilizações e conjunturas críticas comparadas : as "Diretas Já" e o "Fora Collor". Relatório final de pesquisa. Vitória : Departamento de Ciências Sociais, Universidade Federal do 
Espírito Santo.

1995. A massa na praça : mobilização e conflito na campanha das "Diretas Já". Comunicação \& política, Rio de Janeiro, v.1, n. 3, p. 163-178, abr.-jul.

1997. Neoliberalismo : gênese, retórica e prática. Filosofia, sociedade e educação, Marília, ano I, n. I, p. 193-225, jul.

1999. Democracia e mobilização social : participação autônoma e instituições políticas na transição brasileira. Revista de Sociologia e Politica, Curitiba, n. 12, p. 99-119, jun.

2000. O Brasil de Fernando a Fernando. Neoliberalismo, corrupção e protesto na política brasileira de 1989 a 1994. Ijuí (RS) : Unijuí.

SADER, E. 1988. Quando novos personagens entraram em cena. Experiências e lutas dos trabalhadores da Grande São Paulo (19701980). Rio de Janeiro : Paz e Terra.

SALLUM JR., B. 1996. Labirintos : dos generais à Nova República. Rio de Janeiro : Hucitec.

. 1995. Transição política e crise do Estado. In : SOLA, L. \& PAULANI, L. (orgs.). Lições da década de 80. São Paulo : Edusp/Genebra/ UNRISD.

SANTOS, W. G. 1985. A pós-revolução brasileira. In : JAGUARIBE, H. (org.). Brasil: sociedade democrática. Rio de Janeiro : José Olympio.

1988. Paradoxos do liberalismo. São Paulo/Rio de Janeiro : Vértice/IUPERJ.

1993. Razões da desordem. Rio de Janeiro : Rocco.

SAWARD, M. 1994. Democratic Theory and Indices of Democratization. In : BEETHAN, D. (ed.). Defining and Measuring Democracies. London : Sage.

SCHATTSCHNEIDER, E. E. 1967. El pueblo semisoberano. México : Hispano Americana.

SCHMITTER, P. C. \& KARL, T. L. 1995. The Conceptual Travels of Transitologists and Consolidologists : How Far to the East Should They Attempt To Go? Slavic Review, v. 53, n. 1, Spring 1994. Versão revisada : outubro de
1995, digit.

SMELSER, N. 1963. The Theory of Collective Behavior. New York: The Free Press.

TARROW, S. 1988. National Politics and Collective Action : Recent Theory and Research in Western Europe and the United States. Annual Review of Sociology, n. 14.

. 1989. Struggle, Politics and Reform : Collective Action, Social Movements and Cycles of Protest. Ithaca (New York) : Cornell University.

TILLY, C. 1978. From Mobilization to Revolution. London : Addison-Wesley.

1985. Models and Realities of Popular Collective Action. Social Research, New York, v. 52.

TOLEDO, C. N. 1977. ISEB : fábrica de ideologias. São Paulo : Ática.

VELASCO E CRUZ, S. C. 1994. A produção do consenso : discurso econômico e conflitos políticos na transição brasileira. Primeira versão, Campinas, n. 56, set.

. 1997a. Estado e economia em tempo de crise : política industrial e transição política no Brasil dos anos 80. Campinas/São Paulo : Unicamp/Relume-Dumará.

1997b. O impeachment : uma crise singular. In : . O Presente como história : economia e política no Brasil pós-64. Campinas : Unicamp.

1997c. Restructuring World Economy : Arguments about "Market-Oriented Reforms" in Developing Countries. Primeira versão, Campinas, n. 68, fev.

VELASCO E CRUZ, S. C. \& MARTINS, C. E. 1983. De Castelo a Figueiredo : uma incursão na pré-história da abertura. In : SORJ, B. \& ALMEIDA, M. H. T. (orgs.). Sociedade e politica no Brasil pós-64. São Paulo : Brasiliense.

WEFFORT, F. C. 1980. O populismo na política brasileira. Rio de Janeiro : Paz e Terra.

. 1992. Qual democracia? São Paulo : Companhia das Letras. 